\title{
Computed tomography to assess risk of death in acute pulmonary embolism: a meta-analysis
}

\author{
Cecilia Becattini, Giancarlo Agnelli, Federico Germini and Maria Cristina Vedovati
}

Affiliation:

Internal and Cardiovascular Medicine and Stroke Unit, University of Perugia, Perugia, Italy.

Correspondence:

C. Becattini, Internal and Cardiovascular Medicine and Stroke Unit, University of Perugia, Via G Dottori 1 , 06129, Perugia, Italy.

E-mail: cecilia.becattinidunipg.it

ABSTRACT The aim of this study was to evaluate whether right ventricle dilation at computed tomography (CT) angiography can be used to assess the risk of death in patients with acute pulmonary embolism.

Medline and EMBASE were searched up to April 30, 2013. Studies reporting on the association between right ventricle dilation (right-to-left ventricle diameter) or dysfunction (inter-ventricular septal bowing) at CT angiography and death at 30 days, as well as at 3 months in patients with acute pulmonary embolism, were included in a systematic review and meta-analysis.

CT-detected right ventricle dilation was associated with an increased 30 day-mortality in all-comers with pulmonary embolism (OR 2.08 (95\% CI 1.63-2.66); p<0.00001) and in haemodynamically stable patients (OR 1.64 (95\% CI 1.06-2.52); $\mathrm{p}=0.03)$, as well as with death due to pulmonary embolism (OR 7.35 (95\% CI 3.59-15.09); $\mathrm{p}<0.00001)$. An association between right ventricle dilation and 3-month mortality was also observed (OR 4.65 (95\% CI 1.79-12.07); p=0.002).

Right-to-left ventricle dilation as assessed by CT angiography can be used to evaluate risk of death in allcomers with pulmonary embolism and in haemodynamically stable patients.

@ERSpublications

Multidetector CT can be used to assess short-term risk of death in patients with acute pulmonary embolism http://ow.ly/sNcBU

For editorial comments see page 1554 .

This article has supplementary material available from www.erj.ersjournals.com

Received: Aug 232013 | Accepted after revision: Dec 272013 | First published online: March 62014

Conflict of interest: Disclosures can be found alongside the online version of this article at www.erj.ersjournals.com

Copyright @ERS 2014 


\section{Introduction}

Recent guidelines recommend tailoring the clinical management of patients with acute pulmonary embolism to the estimated risk of death $[1,2]$. In these patients, models for risk stratification integrate patient haemodynamic status (mainly presence of shock or hypotension) with markers of myocardial dysfunction or injury [3]. In patients with shock or hypotension, mortality is high and early reperfusion by thrombolysis or embolectomy is recommended without any further risk stratification $[1,2]$. In haemodynamically stable patients, mortality ranges from $<1 \%$ to $10 \%$ [4-6]; this wide range makes risk stratification crucial to drive clinical management. Right ventricle dysfunction or injury are associated with increased mortality in patients with acute pulmonary embolism and have been claimed to be useful to stratify haemodynamically stable patients for the risk of death [7-9].

The assessment of right ventricle dysfunction (echocardiography or brain natriuretic peptide levels) or injury (troponin levels) requires time, is expensive and is not readily available around the clock in several hospitals. Nowadays, computed tomography (CT) angiography is by far the most commonly used method for the diagnosis of acute pulmonary embolism. The development of multi-slice scanners allows accurate visualisation of the heart chambers and pulmonary vessels. Two different methods have been proposed to assess right ventricle dilation on CT angiography. One option is to obtain multiplanar-reconstructed CT images with the aim of recreating the apical 4-chamber view of echocardiography [10]. The second option is to measure heart chambers in the same axial transverse images used to diagnose pulmonary embolism, without reconstructions [11]. The right-to-left ventricle dimension ratio obtained by these methods is by far the most commonly used marker for the assessment of right ventricle dilation at CT angiography in acute pulmonary embolism. Right ventricle dilation at CT angiography has been shown to be associated with an increased risk of death in patients with acute pulmonary embolism [7, 11]. Using these approaches, diagnosis and risk stratification could merge into a single procedure.

We performed a systematic review and a meta-analysis to assess the value of right ventricle dilation or dysfunction at CT angiography to stratify patients with acute pulmonary embolism for risk of death.

\section{Material and methods}

Right-to-left ventricle dimension ratio and inter-ventricular septal (IVS) bowing toward the left ventricle were selected as the markers of right ventricle dilation and right ventricle dysfunction, respectively. We assessed the risk of death associated with these markers in patients with acute pulmonary embolism. The outcomes of the study were death at 30 days and death within 3 months from the index pulmonary embolism. We followed the guidelines and the Meta-Analysis of Observational Studies in Epidemiology (MOOSE) checklist [12].

\section{Search strategy}

We performed an unrestricted search in Medline and EMBASE up to April 30, 2013. Search criteria included the terms "acute pulmonary embolism AND computed tomography". No language restrictions were applied. Reference lists of retrieved articles and review articles were manually searched for other relevant studies. Two authors independently performed the searches and reviewed all identified publications and abstracts for inclusion, using predetermined criteria.

\section{Inclusion criteria}

Studies were included in this review if they reported on patients with: 1) an objective diagnosis of pulmonary embolism; 2) assessment of right ventricle dilation or dysfunction at CT angiography; 3) death at 30 days from diagnosis of pulmonary embolism and/or death within 3 months. Disagreement was solved by consensus with a third investigator and by discussion.

For duplicate publications, the most recent was considered. To assess agreement between reviewers for study selection, we used the $\kappa$ statistic, which measures agreement beyond chance [13].

\section{Data extraction}

For each study, the following data were extracted independently by two authors: general data (study design and year of publication); patients (number, mean age, sex, comorbidities, haemodynamic status and number who received thrombolysis); features of the CT scanner (single or multidetector); markers evaluated at CT angiography (methods for assessment of right ventricle dilation or dysfunction); and clinical outcome (death). The quality of the studies was evaluated using the Newcastle-Ottawa quality assessment scale [14]. 


\section{Selection of studies for meta-analysis}

To be considered for a meta-analysis, a CT-assessed sign of right ventricular dilation or dysfunction had to be reported in at least five studies. Studies were included in the meta-analysis if the following data were available: 1) numbers of patients with/without study outcome in patients with/without a CT feature of right ventricle dilation or dysfunction; or 2) risk measures for death calculated for CT markers of right ventricle dilation or dysfunction. Study authors were contacted to ask for data allowing inclusion in the meta-analysis.

\section{Statistical analysis}

We determined pooled odds ratios (ORs) and 95\% confidence intervals (CI) for death in patients with right ventricle dilation or dysfunction as assessed at CT angiography. We planned separate analyses for: 1) death at 30 days; 2) haemodynamically stable patients; 3) death due to pulmonary embolism; 4) different methods for assessment of right ventricle dilation at CT angiography and different cut-offs; 5) studies reporting on death occurring beyond the hospital stay and between 3 months; and 6) right ventricle dysfunction.

Data were pooled using the Mantel-Haenszel method [15]; we reported results according to a fixed-effects model in the absence of significant heterogeneity and to a random-effects model in the presence of significant heterogeneity [16]. We used the random effects model because it accounts for variations between studies, in addition to sampling error within studies. For studies presenting zero cells, 0.5 was added for a correct estimation of risk measures. For markers of right ventricle dilation or dysfunction that were significantly associated with death, the negative predictive value and the positive predictive value were calculated by meta-analysis of predictive values [17]. The appropriateness of pooling data across studies was assessed using the Cochran's Chi-squared test and the $\mathrm{I}^{2}$ test for heterogeneity. The $\mathrm{I}^{2}$ test measures inconsistency across the study results and describes the proportion of total variation in study estimates that is due to heterogeneity rather than sampling error $[16,18]$. Statistically significant heterogeneity was considered to be present in cases with $\mathrm{p}<0.10$ and $\mathrm{I}^{2}>50 \%$. Funnel plots were used to assess for publication bias [15].

The statistical analyses, forest plots and publication bias analyses were produced with RevMan 5.1 (Cochrane Collaboration, Oxford, UK) and STATA/SE 10.1 (StataCorp, College Station, TX, USA). To be included in the quantitative analysis, studies had to provide sufficient data for calculation of an effect size measure. We calculated the summary ORs with 95\% CI from study-specific ORs taken directly from the study or estimated as crude ORs from cell counts. We also took study specific CIs directly from the study if they were reported or calculated using the corresponding standard error. The study was performed without any external support.

\section{Results}

Overall, 1504 papers were found of which 36 met the inclusion criteria. The flow diagram of literature search and study selection is shown in figure S1. The agreement between reviewers for study selection was good ( $\kappa$ statistic 0.85 ). The main features of the studies are shown in table 1. Eight studies had a prospective design and 27 studies were retrospective. A minimum of 39 and a maximum of 1596 patients were included in the individual studies. Patients were followed for the in-hospital period in seven studies, up to 30 days in 17 studies and from 30 days up to 3 months in 12 studies. Two studies reported on different signs of right ventricle dilation assessed in the same study population. These studies have been included in the metaanalysis, but only one of them has been included in each individual analysis.

\section{Markers of right ventricle dilation at CT-angiography}

Methods for the assessment of right ventricle dilation at CT, features of the scanners and use of image reconstruction [47] are shown in table 2.

In the majority of the studies, right ventricle dilation was assessed as the right-to-left ventricle ratio. 34 studies reported on right-to-left ventricle short-axis diameter ratio, four studies on the right-to-left ventricle volume ratio and one study on the right-to-left ventricle area ratio. Right-to-left ventricle short-axis diameter ratio was assessed in transverse bi-dimensional images in 28 studies and in reconstructed 4-chamber images in 16 studies. Cut-off values for the right-to-left ventricle ratios were different among studies and are reported in table 2.

\section{Meta-analysis of CT assessed right ventricle dilation}

The 36 studies reporting on the prognostic value of right ventricle dilation at CT angiography were further evaluated for inclusion in the meta-analysis. 15 studies were initially excluded $[10,19,20,22,26,31,33,35$, $38,39,41,43,46,50,52]$. For six of them, the inclusion in the analysis was possible following contact with the authors $[22,35,38,39,43,52]$. Among the eight excluded studies, an association between right ventricle dilation at CT and adverse outcome was observed in five studies. 


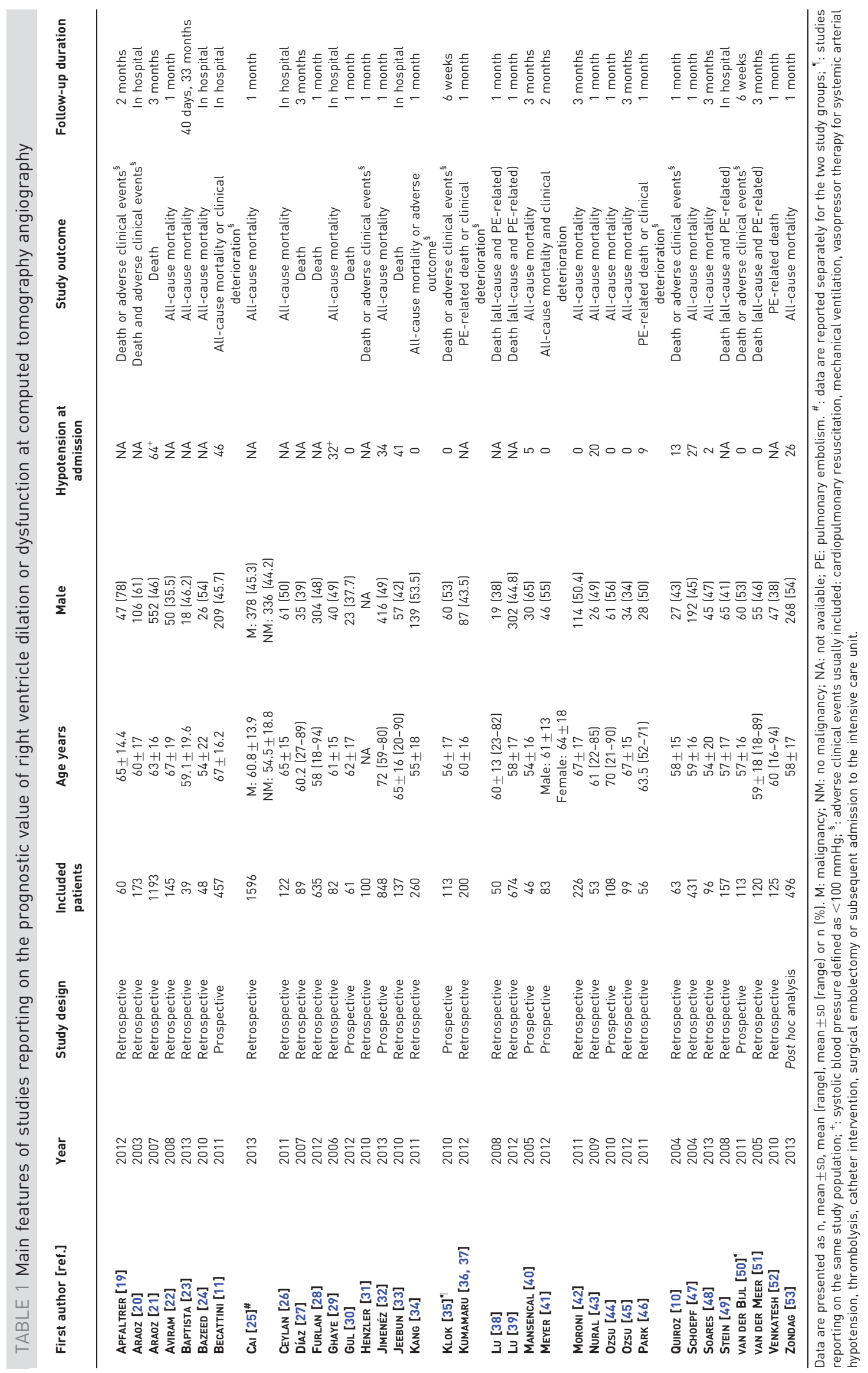


TABLE 2 Features of the scanners and assessment methods of right ventricle dilation or dysfunction

First author [ref.]

CT

Parameters for right ventricle dilation/dysfunction

\begin{tabular}{cc}
\hline CT scanner & Reconstructed \\
image
\end{tabular}

\begin{tabular}{lll}
\hline \multicolumn{2}{l}{ Right-to-left ventricle ratio } & Others \\
\hline Methods & Cut-off
\end{tabular}

\begin{tabular}{|c|c|c|c|c|c|}
\hline APFALTRER [19] & 64 & Both & $\begin{array}{c}\text { Transverse diameter } \\
\text { 4-chamber diameters } \\
\text { Volumes }\end{array}$ & Not reported & \\
\hline ARAOZ [20] & Single or 4 & Both & $\begin{array}{l}\text { Transverse diameters } \\
\text { 4-chamber diameters }\end{array}$ & Not reported & IVS bowing \\
\hline ARAOZ [21] & Single, $4,8,16$ & No & Transverse diameters & Not reported & IVS bowing \\
\hline Aviram [22] & $10,16,40,64$ & Yes & 4-chamber diameters & $>0.9$ & $\begin{array}{l}\text { RV short axis } \\
\text { IVC reflux } \\
\text { IVS bowing }\end{array}$ \\
\hline BAPTISTA [23] & 4,64 & No & Transverse diameters & $>1$ & $\begin{array}{l}\text { RV short axis } \\
\text { LV short axis }\end{array}$ \\
\hline $\begin{array}{l}\text { BazeEd [24] } \\
\text { BeCATtINI [11] }\end{array}$ & $\begin{array}{c}64 \\
4,16\end{array}$ & $\begin{array}{l}\text { Yes } \\
\text { No }\end{array}$ & $\begin{array}{l}\text { Transverse diameters } \\
\text { Transverse diameters }\end{array}$ & $\begin{array}{l}>1 \\
\geqslant 0.9\end{array}$ & RV short axis \\
\hline$C_{A I}[25]$ & $4,16,64$ & Yes & 4-chamber diameters & $>1$ & \\
\hline CEyLan [26] & 16 & Both & $\begin{array}{l}\text { Transverse diameters } \\
\text { 4-chamber diameters }\end{array}$ & Not reported & $\begin{array}{l}\text { SVC diameter } \\
\text { IVS bowing } \\
\text { IVC reflux }\end{array}$ \\
\hline DíAZ [27] & 2 & No & Transverse diameters & $\geqslant 1$ & \\
\hline FURLAN [28] & $16-64$ & Yes & Transverse diameters & $\geqslant 1$ & $\begin{array}{l}\text { RV short axis } \\
\text { LV short axis } \\
\text { SVC diameter } \\
\text { IVC reflux } \\
\text { IVS bowing }\end{array}$ \\
\hline Ghaye [29] & Single & Yes & Transverse diameters & $>1$ & $\begin{array}{l}\text { RV short axis } \\
\text { SVC diameter } \\
\text { IVC reflux } \\
\text { IVS bowing }\end{array}$ \\
\hline GuL [30] & 64 & No & Transverse diameters & $>1$ & PA diameter \\
\hline Henzler [31] & 16,64 & Both & $\begin{array}{c}\text { Transverse diameters } \\
\text { 4-chamber diameters } \\
\text { Volumes }\end{array}$ & Not reported & \\
\hline JIMENÉz [32] & NA & No & Transverse diameters & $>0.9$ & \\
\hline Jeebun [33] & 4 & No & Transverse diameters & Not reported & \\
\hline KANG [34] & 64 & Both & $\begin{array}{c}\text { Transverse diameters } \\
\text { 4-chamber diameters } \\
\text { Volumes }\end{array}$ & $\begin{array}{l}>1 \\
>1 \\
>1.2\end{array}$ & $\begin{array}{l}\text { IVS bowing } \\
\text { IVC reflux }\end{array}$ \\
\hline KLOK [35] & Multi & Yes & $\begin{array}{l}\text { Transverse diameters } \\
\text { 4-chamber diameters }\end{array}$ & $>1$ & \\
\hline KUMAMARU $[36,37]$ & 16,64 & Both & $\begin{array}{l}\text { Transverse diameters } \\
\text { 4-chamber diameters }\end{array}$ & $\begin{array}{c}>0.9^{\bullet} \\
>1\end{array}$ & \\
\hline Lu [38] & 4-64 & Yes & 4-chamber diameters & $>1$ & \\
\hline Lu [39] & $4,16,64$ & Both & $\begin{array}{l}\text { Transverse diameters } \\
\text { 4-chamber diameters }\end{array}$ & $\begin{array}{l}>0.9 \\
>0.9\end{array}$ & \\
\hline Mansencal [40] & 2 & No & Areas & $>1$ & \\
\hline Meyer [41] & 16,64 & Yes & $\begin{array}{c}\text { Transverse diameters } \\
\text { 4-chamber diameters } \\
\text { Volumes }\end{array}$ & Not pre-specified & \\
\hline MoRONI [42] & 4,16 & Yes & Transverse diameters & $>1$ & $\begin{array}{l}\text { IVS bowing } \\
\text { SVC diameter }\end{array}$ \\
\hline NuRal [43] & Single or 16 & No & 4-chamber diameters & Not reported & $\begin{array}{l}\text { RV diameter } \\
\text { SVC diameter } \\
\text { IVS bowing } \\
\text { IVC reflux }\end{array}$ \\
\hline Ozsu [44] & 4,16 & No & Transverse diameters & $\geqslant 1.1$ & \\
\hline Ozsu [45] & 4,16 & No & Transverse diameters & $\geqslant 1.3$ & \\
\hline PARK [46] & 8 & No & Transverse diameters & $>1$ & IVS bowing \\
\hline Quiroz [10] & 4 & Both & $\begin{array}{l}\text { Transverse diameters } \\
\text { 4-chamber diameters }\end{array}$ & $\begin{array}{l}>0.9 \\
>0.9\end{array}$ & \\
\hline SCHOEPF [47] & 4,16 & Yes & 4-chamber diameters & $>0.9$ & \\
\hline SOARES [48] & 64 & Yes & 4-chamber diameters & $\geqslant 0.9$ & \\
\hline STEIN [49] & Multi & No & Transverse diameters & $>1$ & IVS bowing \\
\hline VAN DER BIJL [50] ${ }^{\#}$ & 16,64 & Both & $\begin{array}{c}\text { Transverse diameters } \\
\text { 4-chamber diameters } \\
\text { Volumes }\end{array}$ & $\begin{array}{l}>1 \\
>1 \\
>1.2\end{array}$ & RVEF \\
\hline VAN DeR MeER [51] & Single & No & Transverse diameters & $>1$ & IVS bowing \\
\hline VENKatesh [52] & 4 & No & Transverse diameters & $>0.9^{+}$ & $\begin{array}{l}\text { IVS bowing } \\
\text { RV diameter }\end{array}$ \\
\hline ZONDAG [53] & $4,16,64$ & No & Transverse diameters & $>1$ & \\
\hline
\end{tabular}

CT: computed tomography; IVS: inter-ventricular septum; RV: right ventricle; IVC: inferior vena cava; LV: left ventricle; SVC: superior vena cava; PA: pulmonary artery; RVEF: right ventricular ejection fraction; NA: not available. \#: studies reporting on the same study population; ": data on the same study population have been reported in two publications; ${ }^{+}$: unpublished data. 


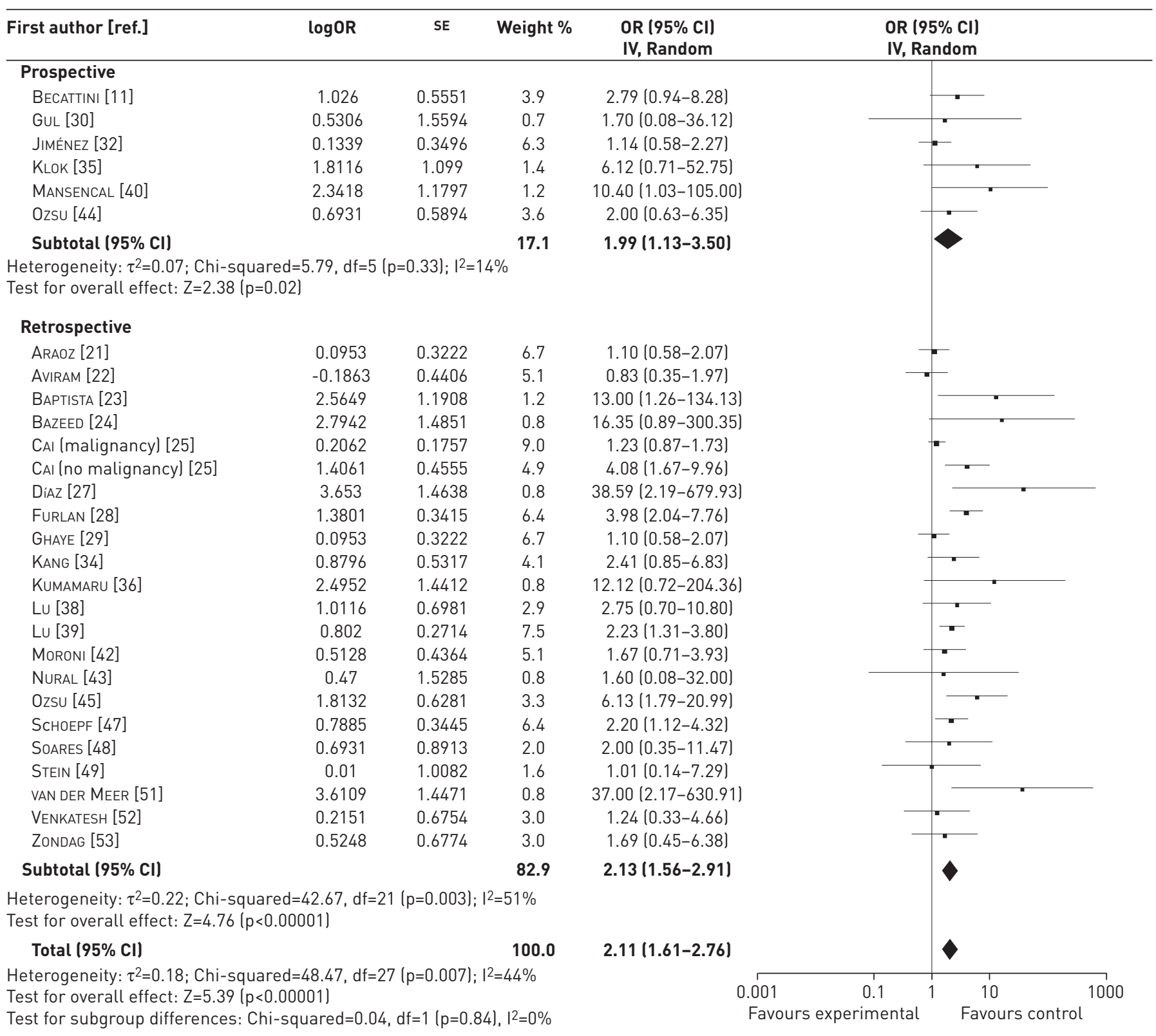

FIGURE 1 Forest plots for death within 3 months. Risk of death in patients with increased or normal right-to-left ventricle ratio. SE: standard error; IV: inverse variance.

Thus, 27 studies (4767 patients) were eligible for inclusion in the meta-analysis of right-to-left ventricle ratio (diameters, areas or volumes) and death within 3 months $[11,21-25,27-30,32,34-36,38-40,42-45$, 47-49, 51-53]. An association was found between an increase of right-to-left ventricle ratio and death; the summary OR calculated by random effects model was 2.11 (95\% CI 1.61-2.76, p < 0.00001 ), with an $\mathrm{I}^{2}$ of $44 \%$ (fig. 1). The association was confirmed in the subgroups of the retrospective (21 studies; OR 2.13 (95\% CI 1.56-2.91); $\mathrm{I}^{2}$ 51\%) and prospective studies (six studies; OR 1.99 (95\% CI 1.13-3.50); I ${ }^{2}$ 14\%) (fig. 1). The funnel plot is presented in figure S2.

The strength of the association was similar in studies conducted with CT scanners of different technical development (mean detector number $\geqslant 16$ or $<16$ ).

Death at 30 days

Among 15 studies reporting on death at 30 days (4661 patients), an association was found between death and right ventricle dilation measured as right-to-left ventricle diameter ratio (OR 2.08 (95\% CI 1.63-2.66); 


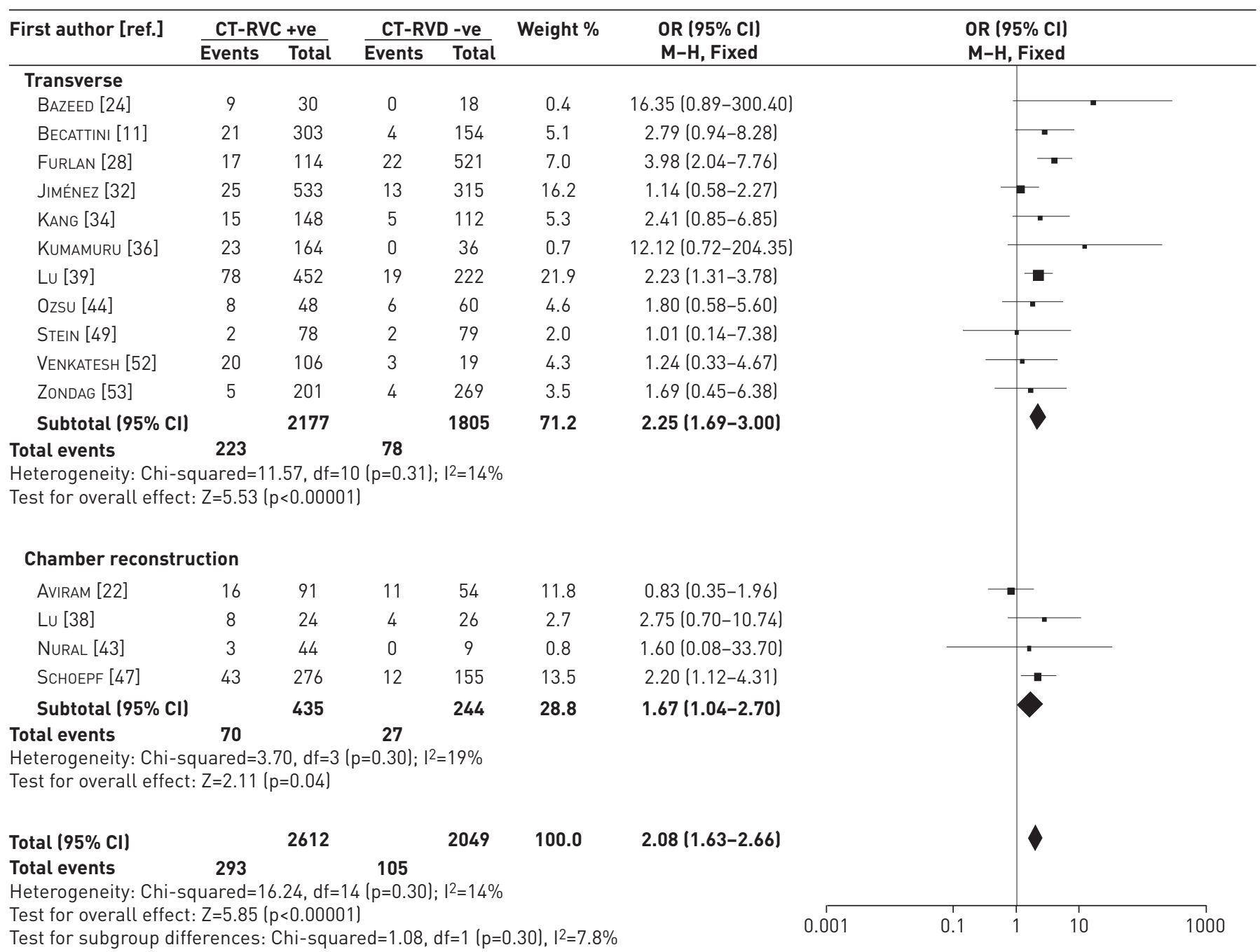

FIGURE 2 Forest plots for death at 30 days. Risk of death in patients with increased right-to-left ventricle ratio. CT-RVD +ve: computed tomography (CT)detected right ventricle dysfunction (RVD) present; CT-RVD -ve: CT-detected RVD absent.

$\mathrm{p}<0.00001, \mathrm{I}^{2} 14 \%$ ) (fig. 2) $[11,22,24,28,32,34,36,38-39,43-44,47,49,52,53]$. The funnel plot is presented in figure S3.

The pooled estimated negative predictive value for right-to-left ventricle diameter ratio measured in transverse images was $95 \%$ (95\% CI 93-97\%) and the positive predictive value was $10 \%$ (95\% CI 6-15\%). The association between death at 30 days and right ventricle dilation was confirmed in a separate analyses for right-to-left ventricle diameter ratio assessed either in transverse images (11 studies, 3982 patients; OR 2.25 (95\% CI 1.69-3.00); $\mathrm{p}<0.00001, \mathrm{I}^{2} 14 \%$ ) or reconstructed 4-chamber views (four studies, 679 patients; OR 1.67 (95\% CI 1.04-2.70); p<0.04, $\mathrm{I}^{2}$ 19\%). Results related to different cut-offs are reported in figures 3 and 4.

Six studies (2254 patients) reported on right-to-left ventricle diameter ratio (all measuring transverse images) in haemodynamically stable patients [11, 32, 34, 44, 49, 53]. The meta-analysis of these studies revealed an increased risk of death at 30 days in patients with right-to-left ventricle diameter ratio, the OR was 1.64 (95\% CI 1.06-2.52; $\mathrm{p}=0.03, \mathrm{I}^{2} 0 \%$ ) (fig. 5). The funnel plot is presented in figure S4.

Eight studies (2925 patients) reported on death due to pulmonary embolism at 30 days [11, 32, 36, 38, 39, $44,49,53]$. Analysing these studies an association was found between right-to-left ventricle ratio and death due to pulmonary embolism (OR 7.35 (95\% CI 3.59-15.09); $\mathrm{p}<0.00001, \mathrm{I}^{2} 16 \%$ ) (fig. S5). The funnel plot is presented in figure S6. The negative predictive value of right-to-left ventricle ratio for death due to pulmonary embolism at 30 days was $99 \%$ (95\% CI 98-100\%) and the positive predictive value was 5\% (95\% CI 2-12\%). Association was confirmed when the analysis was restricted to the seven studies reporting on right-to-left ventricle ratio measured in transverse images (OR 7.78 (95\% CI 3.53-17.14); $\mathrm{I}^{2} 28 \%$ ) 


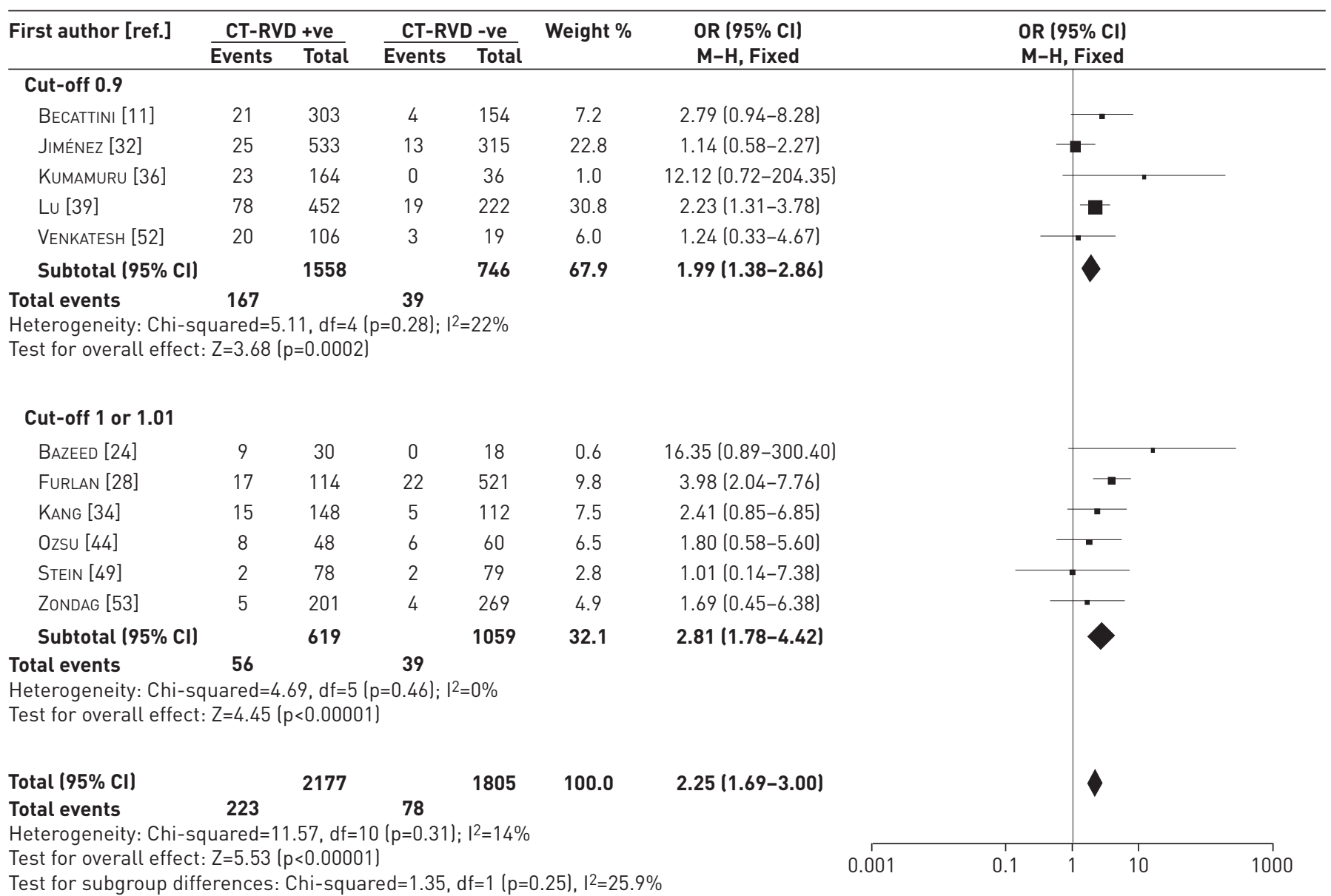

FIGURE 3 Forest plots for death at 30 days. Risk of death in patients with increased right-to-left ventricle ratio as assessed in transverse images. CT-RVD +ve: computed tomography (CT)-detected right ventricle dysfunction (RVD) present; CT-RVD -ve: CT-detected RVD absent.

(fig. S7) and to the five studies specifically reporting on hemodynamically stable patients (1994 patients; OR 3.48 (95\% CI 1.36-8.91); $\mathrm{I}^{2} 0 \%$ ) (fig. S8).

\section{Death within 3 months}

Seven studies (782 patients) reported on right-to-left ventricle diameter ratio and mortality within 3 months from index pulmonary embolism. All but one study reported right-to-left ventricle diameter ratio measured in transverse images [23, 27, 35, 42, 44, 51]. The analysis of these studies showed a significant association between right-to-left ventricle diameter ratio and death; the OR measured by random effects model was 4.65 (95\% CI 1.79-12.07; $\mathrm{p}=0.002)$ with significant heterogeneity $\left(\mathrm{I}^{2} 51 \%\right)$. Five of these studies (647 patients) reported separate data for patients who were haemodynamically stable at presentation $[27,35,41,44,50]$. The analysis of these studies showed a statistically significant association between rightto-left ventricle diameter ratio and death with an OR of 5.14 measured by a random effects model (95\% CI $1.45-18.19, \mathrm{p}=0.01)$, with significant heterogeneity $\left(\mathrm{I}^{2} 63 \%\right)$. The funnel plots did not reveal publication bias in any of the above analyses. Data on the prognostic value of IVS bowing and other CT features are presented in the supplementary material.

\section{Discussion}

This meta-analysis shows that right ventricle dilation at pulmonary CT angiography is associated with an increased risk of death at 30 days in the general population of patients with acute pulmonary embolism, and in those who are haemodynamically stable at diagnosis. The increased risk is confirmed for death due to pulmonary embolism.

The optimal management of haemodynamically stable patients remains one the most controversial issues in patients with acute pulmonary embolism. In these patients, stratification for the risk of death is required to tailor the clinical management. Right ventricle dysfunction, usually assessed by echocardiography, is 


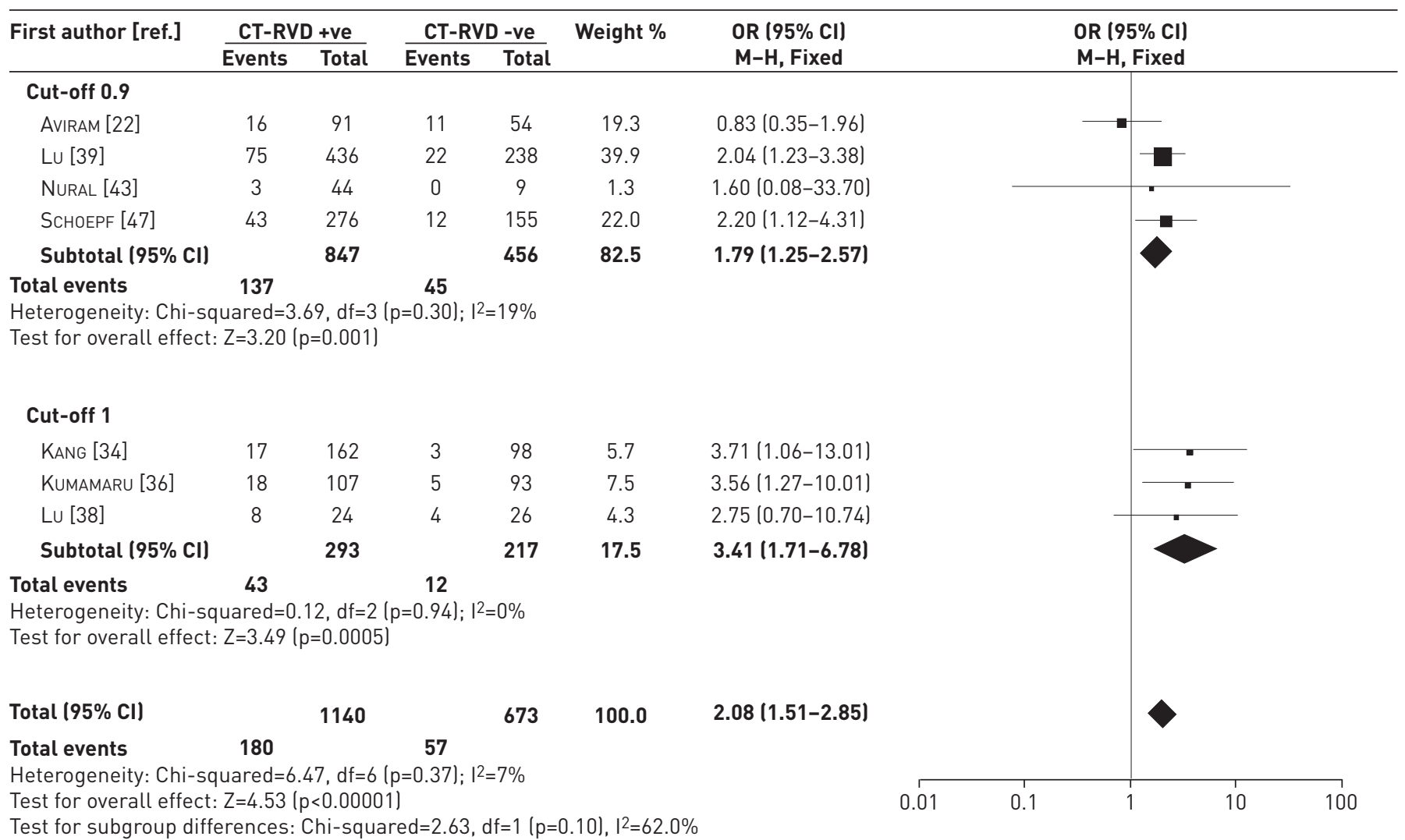

FIGURE 4 Forest plots for death at 30 days. Risk of death in patients with increased right-to-left ventricle ratio as assessed in reconstructed images. CT-RVD +ve: computed tomography (CT)-detected right ventricle dysfunction (RVD) present; CT-RVD -ve: CT-detected RVD absent.

associated with an increased risk of in-hospital death. More recently, a role has been identified for CT angiography in the assessment of right ventricle dilation and, if confirmed, could make risk stratification simpler and rapidly available in an urgent setting. A recently published meta-analysis showed an increased risk of death in patients with sub-massive pulmonary embolism [54]. By confirming this association in both the real "short-term" phase (up to 30 days) and up to 3 months for different CT measurement (transverse and 4-chamber images, and IVS bowing), and in a large population (almost 4000 patients), our study sets the stage for the role of CT angiography in risk stratification in patients with pulmonary embolism. More specifically, our findings support the use of a single test to diagnose pulmonary embolism and to assess the risk of death.

The negative predictive value for death of right ventricle dilation at CT angiography is as high as $95 \%$. However, the $99 \%$ negative predictive value for death due to pulmonary embolism at 30 days allows the identification of haemodynamically stable patients with acute pulmonary embolism who could be managed during a short hospital stay or even as outpatients. The use of the cut-off with high sensitivity for death (right-to-left ventricle ratio $\geqslant 0.9$ ) could improve the safety of this management approach. At present, only one randomised controlled trial has compared home treatment with hospitalisation in patients with acute pulmonary embolism at low risk for death [55]. In this study, low-risk patients were identified using the pulmonary embolism severity index. The accuracy of the HESTIA prediction rule in identifying patients with acute pulmonary embolism who could be candidates for outpatient management was evaluated in a prospective study, and reported promising results [56]. The evaluation of right ventricle dilation at CT angiography could potentially improve the accuracy of clinical prediction rules in the identification of lowrisk patients for outpatient management.

The positive predictive value of right ventricle dilation at CT angiography for death is low $(\sim 10-15 \%)$. This finding is similar to those obtained with echocardiography and biomarkers. Thus, the idea of using one of these markers for treatment upgrading in an individual patient is probably inappropriate. It is conceivable that in patients with right ventricle dilation at CT angiography further risk stratification would improve clinical management. Whether echocardiography or troponin could improve the positive predictive value of 


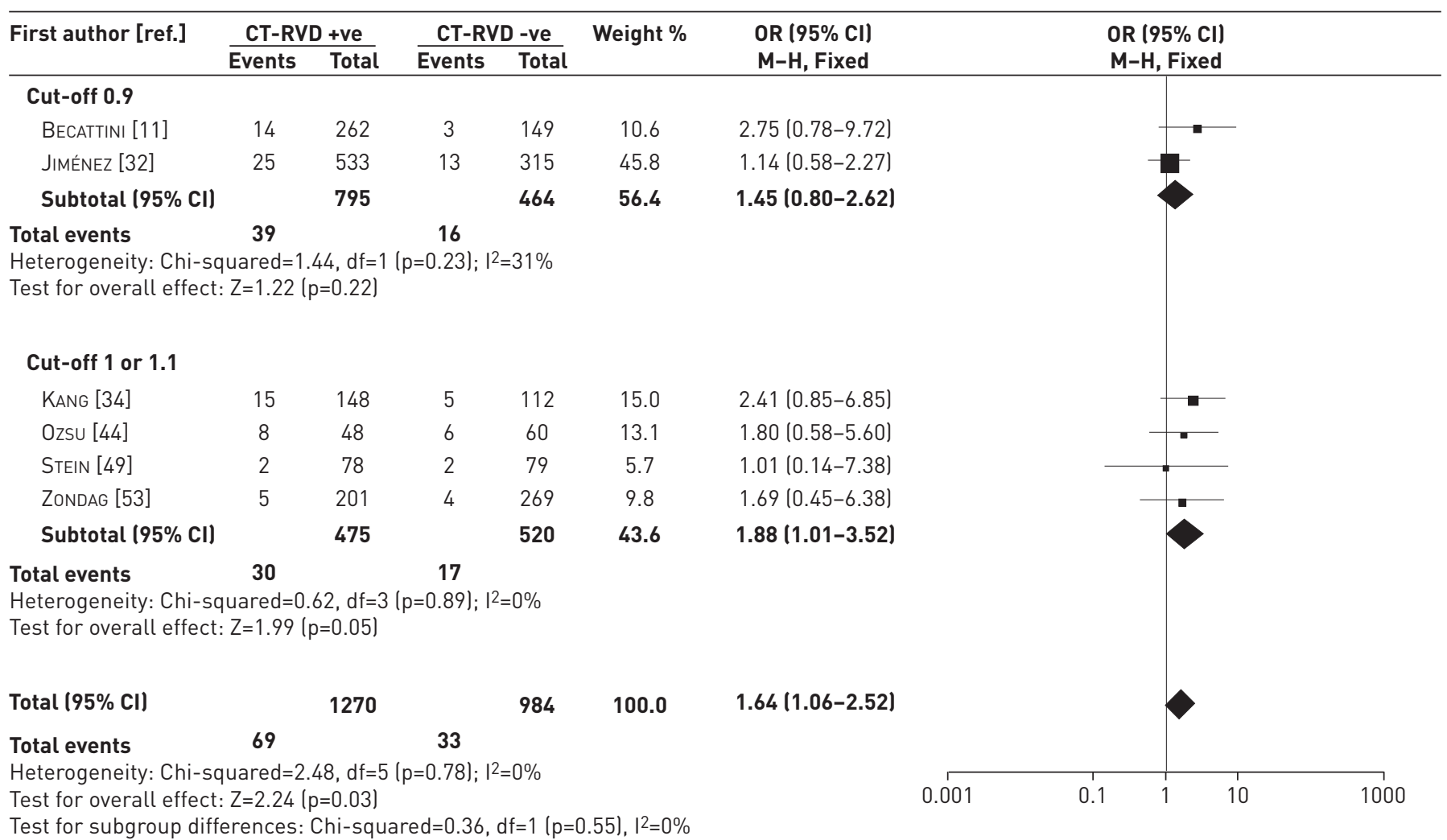

FIGURE 5 Forest plots for death at 30 days in haemodynamically stable patients. Risk of death in haemodynamically stable patients with increased right-to-left ventricle ratio. CT-RVD +ve: computed tomography (CT)-detected right ventricle dysfunction (RVD) present; CT-RVD -ve: CT-detected RVD absent.

CT angiography for death is currently undefined. One prospective study suggested that the combination of right ventricle dilation at CT plus increased troponin could add prognostic value [57]. Currently, no management study aimed at validating a CT-guided approach in patients with acute pulmonary embolism is available. The Pulmonary Embolism Thrombolysis (PEITHO) study aimed at assessing the clinical benefit of thrombolytic therapy compared to placebo in haemodynamically stable patients with right ventricle dysfunction and increased troponin [58]. As a proportion of patients had right ventricle dysfunction diagnosed at CT angiography, this study could provide evidence on a CT angiography-based management strategy in these patients.

Several methods have been proposed for the assessment of right ventricle dilation at CT angiography in patients with acute pulmonary embolism. The right-to-left ventricle diameter ratio is more commonly used to measure right ventricle dilation because it is simple to calculate and mirrors the concept of right ventricle dilation at echocardiography. We found an association between higher cut-offs of right-to-left ventricle diameter ratio and higher risk of death. Different methods were used to assess right-to-left ventricle ratio at CT angiography through the studies included in our critical review. The meta-analyses show that, whatever method is used (diameter ratio, volume ratio or area ratio), right ventricle dilation at CT can be used to stratify patients with acute pulmonary embolism. Indeed, separate analyses showed similar results for transverse or reconstructed images. The evaluation of right ventricle dilation by reconstructed images requires time for reconstruction and measurement. Measurements in transverse images are obtained in the same images used for the diagnosis of pulmonary embolism, which are immediately available at the end of image acquisition with no need for post-processing.

As an additional finding of our analysis, improving scanner technology (number of detectors) does not seem to be associated with an improved prediction of the risk of death associated with right ventricle dilation. It is conceivable that improved technology results in an improved accuracy in the assessment of small lung structures (segmental or sub-segmental arteries).

Our study also shows an association between IVS bowing toward the left ventricle and mortality. Given the limited number of studies reporting on IVS bowing, a separate analysis in haemodynamically stable patients 
was not possible. None of the studies included in our study used an ECG-gated procedure and this could be a limitation for the specific aim of evaluating IVS bowing.

A limitation of the CT approach is it does not allow functional assessments of the right ventricle concerning pulmonary hypertension, right ventricle hypokinesis and tricuspid motion, which are all evaluated by echocardiography.

There are several limitations of our study in addition to those intrinsic to the meta-analysis approach (combining heterogeneous datasets). For example, differences were noted regarding the definition of haemodynamic stability across the studies. In this meta-analysis it was not possible to evaluate interobserver agreement in the assessment of right ventricle dilation or dysfunction at CT. However, interobserver agreement was shown to be good for the evaluation of right-to-left ventricle diameter ratio [11]. Significant heterogeneity was found in the analyses of death occurring beyond 30 days and within 3 months. However, the main clinical implications of risk stratification concern in-hospital management. Thus, the prognostic value at 30 days is of most interest for clinicians.

In conclusion, we found that right ventricle dilation as assessed by CT angiography can be used to identify haemodynamically stable patients with acute pulmonary embolism who are at high and low risk of death and death due to pulmonary embolism. Different management strategies (including home treatment and early discharge) in patients with pulmonary embolism with and without right ventricle dilation at CT angiography should be evaluated in prospective studies.

\section{Acknowledgements}

We would like to acknowledge G. Aviram (Dept of Radiology, Tel Aviv Sourasky Medical Center, Tel Aviv and Sackler Faculty of Medicine, Tel Aviv University, Tel Aviv, Israel), N. Ceylan (Dept of Radiology, Ege University School of Medicine, Izmir, Turkey), A. Furlan (Dept of Radiology, University of Pittsburgh Medical Center, Pittsburgh, PA, USA), F. Klok (Dept of Thrombosis and Haemostasis, Leiden University Medical Center, Leiden, the Netherlands), M.T. Lu (Applied Imaging Science Laboratory, Dept of Radiology, Brigham and Women's Hospital, Harvard Medical School, Boston, MA, USA), M.S. Nural (Faculty of Medicine and Radiology, Ondokuz Mayis University, Samsun, Turkey), F.J. Rybicki (Applied Imaging Science Laboratory, Dept of Radiology, Brigham and Women's Hospital, Harvard Medical School, Boston) and S.K. Venkatesh (Dept of Diagnostic Radiology, National University Hospital, National University Health System, Singapore, Malaysia) for providing unpublished data that were included in this analysis.

\section{References}

1 Torbicki A, Perrier A, Konstantinides S, et al. Guidelines on the diagnosis and management of acute pulmonary embolism: the Task Force for the Diagnosis and Management of Acute Pulmonary Embolism of the European Society of Cardiology (ESC). Eur Heart J 2008; 29: 2276-2315.

2 Jaff MR, McMurtry MS, Archer SL, et al. Management of massive and submassive pulmonary embolism, iliofemoral deep vein thrombosis, and chronic thromboembolic pulmonary hypertension: a scientific statement from the American Heart Association. Circulation 2011; 123: 1788-1830.

Agnelli G, Becattini C. Acute pulmonary embolism. N Engl J Med 2010; 363: 266-274.

4 Goldhaber SZ, Visani L, De Rosa M. Acute pulmonary embolism: clinical outcomes in the International Cooperative Pulmonary Embolism Registry (ICOPER). Lancet 1999; 353: 1386-1389.

5 Konstantinides S, Geibel A, Olschewski M, et al. Association between thrombolytic treatment and the prognosis of hemodynamically stable patients with major pulmonary embolism: results of a multicenter registry. Circulation 1997; 96: 882-888.

6 Pollack CV, Schreiber D, Goldhaber SZ, et al. Clinical characteristics, management, and outcomes of patients diagnosed with acute pulmonary embolism in the emergency department: initial report of EMPEROR (Multicenter Emergency Medicine Pulmonary Embolism in the Real World Registry). J Am Coll Cardiol 2011; 57: 700-706.

7 Sanchez O, Trinquart L, Colombet I, et al. Prognostic value of right ventricular dysfunction in patients with haemodynamically stable pulmonary embolism: a systematic review. Eur Heart J 2008; 29: 1569-1577.

8 Klok FA, Mos IC, Huisman MV. Brain-type natriuretic peptide levels in the prediction of adverse outcome in patients with pulmonary embolism: a systematic review and meta-analysis. Am J Respir Crit Care Med 2008; 178: 425-430.

9 Becattini C, Vedovati MC, Agnelli G. Prognostic value of troponins in acute pulmonary embolism: a meta-analysis. Circulation 2007; 116: 427-433.

10 Quiroz R, Kucher N, Schoepf UJ, et al. Right ventricular enlargement on chest computed tomography: prognostic role in acute pulmonary embolism. Circulation 2004; 109: 2401-2404.

11 Becattini C, Agnelli G, Vedovati MC, et al. Multidetector computed tomography for acute pulmonary embolism: diagnosis and risk stratification in a single test. Eur Heart J 2011; 32: 1657-1663.

12 Stroup DF, Berlin JA, Morton SC, et al. Meta-analysis of observational studies in epidemiology: a proposal for reporting. Meta-analysis Of Observational Studies in Epidemiology (MOOSE) group. JAMA 2000; 283: 2008-2012.

13 McGinn T, Wyer PC, Newman TB, et al. Tips for learners of evidence-based medicine: 3. Measures of observer variability (kappa statistic). CMAJ 2004; 171: 1369-1373.

14 Wells GA, Shea B, O'Connell D, et al. The Newcastle-Ottawa scale (NOS) for assessing the quality of nonrandomised studies in meta-analyses. Ottawa Hospital Research Institute, 2011. www.ohri.ca/programs/ clinical_epidemiology/oxford.asp Date last accessed: August 20, 2013.

15 Egger M, Smith GD, Altman DG, eds. Systematic Reviews in Health Care: Meta-Analysis in Context. 2nd Edn. Oxford, Wiley-Blackwell, 2001.

16 Higgins JP, Thompson SG. Quantifying heterogeneity in a meta-analysis. Stat Med 2002; 21: 1539-1558. 
17 Leeflang MM, Deeks JJ, Rutjes AW, et al. Bivariate meta-analysis of predictive values of diagnostic tests can be an alternative to bivariate meta-analysis of sensitivity and specificity. J Clin Epidemiol 2012; 65: 1088-1097.

18 Cochran WG. The combination of estimates from different experiments. Biometrics 1954; 10: 101-129.

19 Apfaltrer P, Bachmann V, Meyer M, et al. Prognostic value of perfusion defect volume at dual energy CTA in patients with pulmonary embolism: correlation with CTA obstruction scores, CT parameters of right ventricular dysfunction and adverse clinical outcome. Eur J Radiol 2012; 81: 3592-3597.

20 Araoz PA, Gotway MB, Trowbridge RL, et al. Helical CT pulmonary angiography predictors of in-hospital morbidity and mortality in patients with acute pulmonary embolism. $J$ Thorac Imaging 2003; 18: 207-216.

21 Araoz PA, Gotway MB, Harrington JR, et al. Pulmonary embolism: prognostic CT findings. Radiology 2007; 242: 889-897.

22 Aviram G, Rogowski O, Gotler Y, et al. Real-time risk stratification of patients with acute pulmonary embolism by grading the reflux of contrast into the inferior vena cava on computerized tomographic pulmonary angiography. J Thromb Haemost 2008; 6: 1488-1493.

23 Baptista R, Santiago I, Jorge E, et al. One-shot diagnostic and prognostic assessment in intermediate- to high-risk acute pulmonary embolism: the role of multidetector computed tomography. Rev Port Cardiol 2013; 32: 7-13.

24 Bazeed MF, Saad A, Sultan A, et al. Prediction of pulmonary embolism outcome and severity by computed tomography. Acta Radiol 2010; 51: 271-276.

25 Cai B, Bedayat A, George E, et al. Malignancy and acute pulmonary embolism: risk stratification including the right to left ventricle diameter ratio in 1596 subjects. J Thorac Imaging 2013; 28: 196-201.

26 Ceylan N, Tasbakan S, Bayraktaroglu S, et al. Predictors of clinical outcome in acute pulmonary embolism: correlation of CT pulmonary angiography with clinical, echocardiography and laboratory findings. Acad Radiol 2011; 18: 47-53.

27 Díaz JC, Ladrón de Guevara D, Pereira G, et al. Medición de la carga embolica y relación ventrículo derecho/ ventrículo izquierdo en tomografía computada como indicadores de riesgo en pacientes con tromboembolismo pulmonar [Predictive values for mortality in pulmonary embolism, of embolic load and right/left ventricular diameter ratio, measured by computed tomography]. Rev Med Chil 2007; 135: 1437-1445.

28 Furlan A, Aghayev A, Chang CC, et al. Short-term mortality in acute pulmonary embolism: clot burden and signs of right heart dysfunction at CT pulmonary angiography. Radiology 2012; 265: 283-293.

29 Ghaye B, Ghuysen A, Willems V, et al. Severe pulmonary embolism:pulmonary artery clot load scores and cardiovascular parameters as predictors of mortality. Radiology 2006; 239: 884-891.

30 Gul EE, Can I, Guler I, et al. Association of pulmonary artery obstruction index with elevated heart-type fatty acid binding protein and short-term mortality in patients with pulmonary embolism at intermediate risk. Diagn Interv Radiol 2012; 18: 531-536.

31 Henzler T, Krissak R, Reichert M, et al. Volumetric analysis of pulmonary CTA for the assessment of right ventricular dysfunction in patients with acute pulmonary embolism. Acad Radiol 2010; 17: 309-315.

32 Jiménez D, Lobo JL, Monreal M, et al. Prognostic significance of multidetector CT in normotensive patients with pulmonary embolism: results of the protect study. Thorax 2014; 69: 109-115.

33 Jeebun V, Doe SJ, Singh L, et al. Are clinical parameters and biomarkers predictive of severity of acute pulmonary emboli on CTPA? QJM 2010; 103: 91-97.

34 Kang DK, Thilo C, Schoepf UJ, et al. CT signs of right ventricular dysfunction: prognostic role in acute pulmonary embolism. JACC Cardiovasc Imaging 2011; 4: 841-849.

35 Klok FA, Van Der Bijl N, Eikenboom HC, et al. Comparison of CT assessed right ventricular size and cardiac biomarkers for predicting short-term clinical outcome in normotensive patients suspected of having acute pulmonary embolism. J Thromb Haemost 2010; 8: 853-856.

36 Kumamaru KK, Hunsaker AR, Wake $\mathrm{N}$, et al. The variability in prognostic values of right ventricular-to-left ventricular diameter ratios derived from different measurement methods on computed tomography pulmonary angiography: a patient outcome study. J Thorac Imaging 2012; 27: 331-336.

37 Kumamaru KK, Hunsaker AR, Bedayat A, et al. Subjective assessment of right ventricle enlargement from computed tomography pulmonary angiography images. Int J Cardiovasc Imaging 2012; 28: 965-973.

38 Lu MT, Cai T, Ersoy H, et al. Interval increase in right-left ventricular diameter ratios at CT as a predictor of 30-day mortality after acute pulmonary embolism: initial experience. Radiology 2008; 246: 281-287.

39 Lu MT, Demehri S, Cai T, et al. Axial and reformatted four-chamber right ventricle-to-left ventricle diameter ratios on pulmonary CT angiography as predictors of death after acute pulmonary embolism. AJR Am J Roentgenol 2012; 198: 1353-1360.

40 Mansencal N, Joseph T, Vieillard-Baron A, et al. Diagnosis of right ventricular dysfunction in acute pulmonary embolism using helical computed tomography. Am J Cardiol 2005; 95: 1260-1263.

41 Meyer M, Fink C, Roeger S, et al. Benefit of combining quantitative cardiac CT parameters with troponin I for predicting right ventricular dysfunction and adverse clinical events in patients with acute pulmonary embolism. Eur J Radiol 2012; 81: 3294-3299.

42 Moroni AL, Bosson JL, Hohn N, et al. Non-severe pulmonary embolism: prognostic CT findings. Eur J Radiol 2011; 79: 452-458.

43 Nural MS, Elmali M, Findik S, et al. Computed tomographic pulmonary angiography in the assessment of severity of acute pulmonary embolism and right ventricular dysfunction. Acta Radiol 2009; 50: 629-637.

44 Ozsu S, Karaman K, Mentese A, et al. Combined risk stratification with computerized tomography/ echocardiography and biomarkers in patients with normotensive pulmonary embolism. Thromb Res 2010; 126: 486-492.

45 Ozsu S, Abul Y, Yilmaz I, et al. Prognostic significance of $\mathrm{PaO}_{2} / \mathrm{PaCO}_{2}$ ratio in normotensive patients with pulmonary embolism. Clin Respir J 2012; 6: 104-111.

46 Park JR, Chang SA, Jang SY, et al. Evaluation of right ventricular dysfunction and prediction of clinical outcomes in acute pulmonary embolism by chest computed tomography: comparisons with echocardiography. Int J Cardiovasc Imaging 2012; 28: 979-987.

47 Schoepf UJ, Kucher N, Kipfmueller F, et al. Right ventricular enlargement on chest computed tomography: a predictor of early death in acute pulmonary embolism. Circulation 2004; 110: 3276-3280. 
Soares TH, de Bastos M, de Carvalho BV, et al. Prognostic value of computed tomographic pulmonary angiography and the pulmonary embolism severity index in patients with acute pulmonary embolism. Blood Coagul Fibrinolysis 2013; 24: 64-70.

49 Stein PD, Beemath A, Matta F, et al. Enlarged right ventricle without shock in acute pulmonary embolism: prognosis. Am J Med 2008; 121: 34-42.

50 van der Bijl N, Klok FA, Huisman MV, et al. Measurement of right and left ventricular function by ECGsynchronized CT scanning in patients with acute pulmonary embolism: usefulness for predicting short-term outcome. Chest 2011; 140: 1008-1015.

51 van der Meer RW, Pattynama PM, van Strijen MJ, et al. Right ventricular dysfunction and pulmonary obstruction index at helical CT: prediction of clinical outcome during 3-month follow-up in patients with acute pulmonary embolism. Radiology 2005; 235: 798-803.

52 Venkatesh SK, Wang SC. Central clot score at computed tomography as a predictor of 30-day mortality after acute pulmonary embolism. Ann Acad Med Singapore 2010; 39: 442-447.

53 Zondag W, Vingerhoets LM, Durian MF, et al. Hestia criteria can safely select patients with pulmonary embolism for outpatient treatment irrespective of right ventricular function. J Thromb Haemost 2013; 11: 686-692.

54 Trujillo-Santos J, den Exter PL, Gómez V, et al. Computed tomography-assessed right ventricular dysfunction and risk stratification of patients with acute non-massive pulmonary embolism: systematic review and meta-analysis. J Thromb Haemost 2013; 11: 1823-1832.

55 Aujesky D, Roy PM, Verschuren F, et al. Outpatient versus inpatient treatment for patients with acute pulmonary embolism: an international, open-label, randomised, non-inferiority trial. Lancet 2011; 378: 41-48.

56 Zondag W, Mos IC, Creemers-Schild D, et al. Outpatient treatment in patients with acute pulmonary embolism: the Hestia Study. J Thromb Haemost 2011; 9: 1500-1507.

57 Becattini C, Casazza F, Forgione C, et al. Acute pulmonary embolism: external validation of an integrated risk stratification model. Chest 2013; 144: 1539-1545.

58 Steering Committee. Single-bolus tenecteplase plus heparin compared with heparin alone for normotensive patients with acute pulmonary embolism who have evidence of right ventricular dysfunction and myocardial injury: rationale and design of the Pulmonary Embolism Thrombolysis (PEITHO) trial. Am Heart J 2012; 163: 33-38. 